\section{Due Dates}

The National Science Foundation (NSF) Observing Facilities Advisory Panel (OFAP) will meet in October 1995 and April 1996 to consider requests for use of all NSF-sponsored lower-atmospheric observing facilities. These include facilities at the National Center for Atmospheric Research's (NCAR) Atmospheric Technology Division, University of Wyoming, Colorado State University, and South Dakota School of Mines and Technology. OFAP evaluates requests and makes recommendations on allocations to the NSF Facilities Advisory Council.

Due dates for receipt of requests for consideration at the October 1995 and April 1996 OFAP meetings are 15 June 1995 (for requested facility use between 1 April 1996 and 30 September 1996) and 15 December 1995 (for requested facility use between 1 October 1996 and 31 March 1997). The OFAP meets in April and October of each year; due dates for requests are always in mid-December for the April meeting and in mid-June for the October meeting.

Scientists requesting facility support in conjunction with NSF grants should include those requirements in their grant applications, which are also due at NSF on the same dates.

Detailed information including where to send facilities requests is available via the Internet on the NCAR Gopher and via Mosaic on the NCAR/ATD home page, http://www.atd.ucar.edu. Alternatively, prospective requestors can contact Shelley Zucker of NCAR/ ATD at 303-497-8833; e-mail: zucker@ncar.ucar.edu for additional information.

\section{Interactive Computer System}

For the first time ever, anyone anywhere with a computer and modem (including classroom teachers and their students) will be able to quickly access free weather data, graphics, and any other data from one local television station and transmit information to the station as well. It is a part of a new interactive educational, sales, and marketing system called ViewerNET ${ }^{\circledR}$.

The new system supplies licensed television stations with easy-to-install weather stations that can be placed in local schools or any other site from which weather information is desired. The television station's news and weather departments can then instantly access weather conditions from the remote site on demand. In addition to the ability to broadcast the realtime weather information from their viewing area, ViewerNET television stations can also use the system to provide their audience with weather forecasts, brief program or news notes, weather map graphics, and sponsor messages. In addition, any other viewer or classroom with just a computer and modem can transmit or receive information with the ViewerNET television station using the stand-alone computer software (available in Macintosh or Windows compatible formats).

\section{Weather Conference}

The Mount Washington Observatory will be conducting a weather conference on 23-24 June 1995 in North Conway, New Hampshire. The two-day event, which will be the Fourth Annual Observatory Symposium, will feature topics of interest both to meteorologists and to laypersons with a general interest in the weather.

The first day of the conference will focus on wind, ice, and fog. Topics will include atmospheric icing, trends in meteorological equipment and sensors, data acquisition systems, and automated weather stations.

The second day will feature discussions of weather forecasting and global climate change and panel presentations on establishing a personal weather station, historic weather events, and bringing weather into a classroom. AMS member and past-president Charles Hosler is the keynote speaker and Bruce Schwoegler will serve as the master of ceremonies.

For additional information about the weather conference, contact the Mount Washington Observatory Symposium, P.O. Box 2310, North Conway, NH03860; telephone: 603-356-8345.

\section{Air Weather Association}

The professional organization composed of present and former members of the U.S. Air Force (USAF) Air Weather Service and of the U.S. Army Air Corps Weather Service has established its own home page on the Internet. The Air Weather Association's home page is URL http://www.infi.net/ cwt/awa.html. The site is recognized by USAF Headquarters and is linked in a prominent location on the official USAF Headquarters main Web server and on the USAF Headquarters home page: http://www.hq.af.mil/USAF/USAF. html\#OTHER. 